\title{
Immune-related adverse events: a retrospective look into the future of oncology in the intensive care unit
}

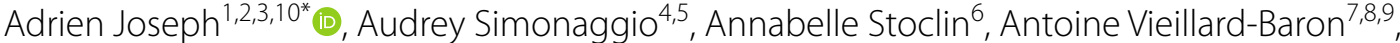 \\ Guillaume Geri ${ }^{7,8,9}$, Stéphane Oudard ${ }^{4,5}$, Jean-Marie Michot ${ }^{11}$, Olivier Lambotte ${ }^{10,12,13}$, Elie Azoulay 3,14 \\ and Virginie Lemiale ${ }^{3}$
}

\begin{abstract}
Background: Immune checkpoint inhibitors have reshaped the standard of care in oncology. However, they have been associated with potentially life-threatening immune-related adverse events. With the growing indications of immune checkpoint inhibitors and their position as a pillar of cancer treatment, intensive care physicians will be increasingly confronted with their side effects. The outcome of patients with severe immune-related adverse events in the intensive care unit remains unknown. This retrospective multicentric study aims to describe the characteristics of patients admitted to the intensive care units of 4 academic hospitals in Paris area while receiving immune checkpoint inhibitor treatment between January 2013 and October 2019.

Results: Over the study period, 112 cancer patients who received immune checkpoint inhibitors were admitted to the intensive care unit within 60 days after the last dose. ICU admission was related to immune-related adverse events $(n=29,26 \%)$, other intercurrent events $(n=39,35 \%)$, or complications related to tumor progression $(n=44$, 39\%). Immune-related adverse events were pneumonitis $(n=8)$, colitis $(n=4)$, myocarditis $(n=3)$, metabolic disorders related to diabetes $(n=3)$, hypophysitis $(n=2)$, nephritis $(n=2)$, meningitis or encephalitis $(n=2)$, hepatitis $(n=2)$, anaphylaxis $(n=2)$ and pericarditis $(n=1)$. Primary tumors were mostly melanomas ( $n=14,48 \%)$, non-small-cell lung cancers $(n=7,24 \%)$, and urothelial carcinomas $(n=5,17 \%)$. Diagnosis of melanoma and a neutrophil/lymphocyte ratio $<10$ were associated with immune-related diagnosis versus other reasons for ICU admission. During their ICU stay, immune-related adverse events patients needed vasopressors $(n=7)$, mechanical ventilation $(n=6)$, and extracorporeal membrane oxygenation $(n=2)$. One-year survival was significantly higher for patients admitted for irAE compared to patients admitted for other reasons $(p=0.004)$.
\end{abstract}

Conclusions: Admission to the intensive care unit related to immune-related adverse event was associated with better outcome in cancer patients treated with immune checkpoint inhibitors. Our results support the admission for an intensive care unit trial for patients with suspected immune-related adverse events.

Keywords: Cancer, Outcome, Adverse event, Immunotherapy, Intensive care, Immune-related adverse events, Immune checkpoint inhibitor

*Correspondence: adrien.joseph@hotmail.fr

${ }^{1}$ U1138. INSERM, Équipe 11 labellisée Ligue Nationale Contre Le Cancer, « Metabolism, Cancer \& Immunity », Centre de Recherche Des Cordeliers,

15. rue de l'École de Médecine, 75006 Paris, France

Full list of author information is available at the end of the article

\section{Background}

Immune checkpoint inhibitors (ICI) have revolutionized cancer care and have led to a significant survival improvement in a large variety of tumors [1].

Pharmaceutical specialties currently approved enhance antitumor immunity by reversing tumor escape caused
Springer Open

(c) The Author(s) 2020. This article is licensed under a Creative Commons Attribution 4.0 International License, which permits use, sharing, adaptation, distribution and reproduction in any medium or format, as long as you give appropriate credit to the original author(s) and the source, provide a link to the Creative Commons licence, and indicate if changes were made. The images or other third party material in this article are included in the article's Creative Commons licence, unless indicated otherwise in a credit line to the material. If material is not included in the article's Creative Commons licence and your intended use is not permitted by statutory regulation or exceeds the permitted use, you will need to obtain permission directly from the copyright holder. To view a copy of this licence, visit http://creativeco mmons.org/licenses/by/4.0/. 
by two negative regulators: cytotoxic T-lymphocyte antigen 4 (CTLA-4) and programmed cell death 1 (PD-1) or its ligand, programmed cell death ligand 1 (PD-L1).

Since the early 2010s, with ICIs coming of age and the tremendous interest they engendered, a new profile of toxicity also revealed itself. Termed immune related adverse events (irAEs), the side effects of these novel therapeutic antibodies result from the loss of immune homeostasis and off-target effects in peripheral tissues [2, 3]. Although the skin, endocrine glands and digestive tract are mostly affected, pulmonary [4-6], neurologic [7-10], hepatic [11-13] and cardiologic [14-19] side effects have also been described and may be life-threatening.

The best standard of care for irAEs has not been established through randomized trials and research on the subject is considered an urgent need [6], but guidelines based on experts' opinion often place steroids as a firstline therapy [20,21], followed by other immunosuppressive therapies according to the type of irAE and the organ involved [22-25].

With the growing indications of ICI and their position as a pillar of cancer treatment, intensive care physicians will be increasingly confronted with their side effects.

The outcome of patients admitted to the ICU for irAEs remains unknown and may potentially differ from other oncological complications of patients admitted to the ICU [26].

This study aims to describe the characteristics of cancer patients receiving ICI and admitted to the ICU. Patients admitted for irAE were compared to patients admitted for other reasons.

\section{Methods}

We conducted a retrospective multicentric study including patients from 4. French university hospitals in Paris area. All centers were oncologic centers and were organized with a multidisciplinary board [27] to discuss the management of immune-related adverse events. Patients eligible were admitted to ICUs between January 2013 and October 2019, during the course of an ICI treatment (either anti-PD-1 (NIVOLUMAB, PEMBROLIZUMAB or SPARTALIZUMAB), anti-PDL-1 (ATEZOLIZUMAB, DURVALUMAB), anti-CTLA4 (IPILIMUMAB or TREMELIMUMAB) or a combination of ICI.

All consecutive adult patients admitted to the ICU who were receiving an ICI treatment for solid or hematological malignancy were included in the study. Patients admitted for less than $24 \mathrm{~h}$ in the ICU or patients who had stopped ICI treatment for more than 60 days before admission were not included. Investigational immunotherapies relying on inhibition of other checkpoints or mechanisms other than immune checkpoint inhibition and non-systemically administered immunotherapies were excluded.

All data were extracted from medical charts. Followup until 1 year after ICU admission was recorded.

Patients were then classified according to the reason for admission, whether related to an immune-related adverse event (irAE), an intercurrent adverse event not related to immunotherapy (intE) or a complication related to tumor progression (TumProg). Imputability of the ICI for irAEs was assessed by the physician in charge, discussed in multidisciplinary boards in most cases [27] and reviewed by investigators (AJ and $\mathrm{VL}$ ), according to the World Health Organization Uppsala Monitoring Centre scale for standardized case causality assessment and organ-specific guidelines when available [16]. Tumor progression was defined as peritumoral hemorrhage, tumor obstruction or lymphangitis carcinomatosis. Intercurrent event was defined as any other medical condition neither related to tumor progression nor irAE. In case of concomitant tumor progression and immune-related or intercurrent event, the patient was classified a posteriori according to the reason for ICU admission as assessed by the physician in charge and reviewed by investigators (AJ and $\mathrm{VL}$ ).

\section{Statistical analysis}

Results were expressed as median and 25th and 75th quartiles [Q1-Q3] for quantitative data and numbers and percentages for categorical data. Quantitative variables were compared using the Wilcoxon test, and qualitative variables were compared using the Chisquare test with Yate's continuity correction if needed. Baseline demographical, oncological, clinical and biological characteristics at ICU admission were described in the first table and relevant variables were tested for their association with irAE diagnosis (Fisher's test) and 1-year mortality (logistic regression). A multivariate logistic regression model included variables that were significantly associated with 1-year mortality in univariate logistic regression and clinically relevant variables. Kaplan-Meier curves until 1 year after ICU admission were stratified using significant variables and compared using log-rank tests. Follow-up of patients after discharge from the ICU until death or end of followup was represented in a swimmer plot, where different colors represent different types of irAEs. Reintroduction of an ICI and complete responses according to iRECIST [28] were depicted by pictograms. All statistical tests were two-sided with an $\alpha$ level of 0.05 . Statistics were managed using $\mathrm{R}$ software version 3.4.2 ( $\mathrm{R}$ Foundation for Statistical Computing, Vienna, Austria; https://www.R-project.org/). 


\section{Results}

Between January 2013 and October 2019, 5644 cancer patients were admitted to the ICU and 112 of them (2\%) were admitted within 60 days after an administration of ICI. Among them, 29 (26\%) patients were admitted for an irAE, 44 (39\%) patients were admitted for a complication related to tumor progression (TumProg) and 39 (35\%) patients had another reason for ICU admission (intE) (Additional file 1: Figure S1).

The absolute number of patients admitted within the course of an immunotherapy showed a significant increase from 2013 to 2018 (Mann-Kendall test $p=0.024)$, whereas the proportion of irAEs within these years remained stable (Chi-squared test for trend $p=0.298$ ) (Fig. 1).

Altogether, patients admitted to the ICU within the course of an ICI treatment were mostly males $(n=68 / 112,60.7 \%)$, had a median age of 64.7 [52.171.2] years and 61/112 (54.4\%) had a performance status of 0 or 1 . The most frequent malignancies were melanoma $(n=30 / 112,26.8 \%)$, non-small cell lung cancer (NSCLC) $(n=32 / 112,28.6 \%)$ and head and neck cancer $(\mathrm{n}=15 / 112,13.4 \%)$ (Additional file 2: Figure S2 panel B). Ninety-five patients $(84.8 \%)$ had a metastatic disease at the time of admission.

Median time from ICI initiation to ICU admission was 51.5 [20.8-117.4] days, with a median 14 [7-27] days since last dose. Median Sequential Organ Failure Assessment (SOFA) score at admission was 4 [1-5].

Median ICU stay was 3 [1-5] days and 30/112 (26.8\%) patients died in the ICU.

Fifteen patients (irAE $(n=5)$, intE $(n=7)$ and TumProg $(n=3), 13.4 \%)$ were lost to follow-up and $67 / 97$ patients $(69.1 \%)$ died before 1 year after ICU admission.

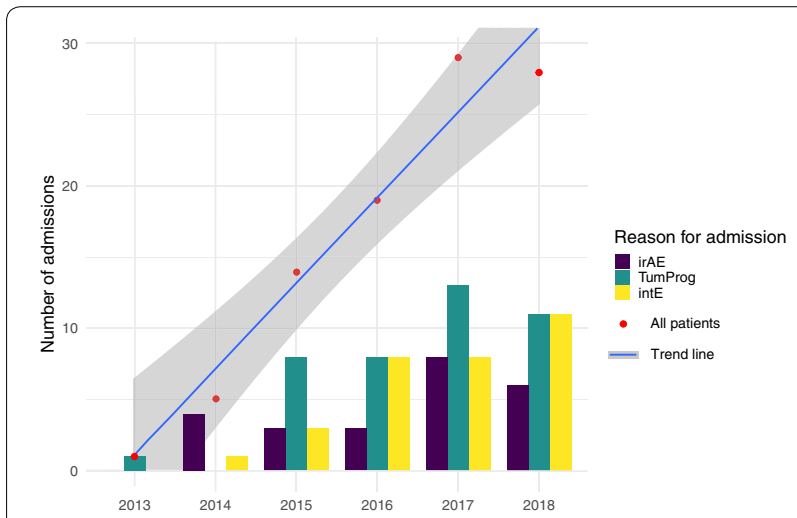

Fig. 1 Bar plots of the number and reasons for admission over the study period ( $p<0.001)$. irAE immune-related adverse event, TumProg complication related to tumor progression, intE intercurrent event

\section{Patients with irAE}

Diagnoses of irAEs included pneumonitis $(n=8 / 29$, $27.6 \%)$, colitis $(n=4 / 29,13.8 \%)$, myocarditis $(n=3 / 29$, $10.3 \%$ ), metabolic disorder related to hypophysitis $(n=2 / 29,6.9 \%)$ or diabetes mellitus $(n=3 / 29,10.3 \%)$, nephritis $(n=2 / 29,6.9 \%)$, hepatitis $(n=2 / 29,6.9 \%)$, infusion-related hypersensitivity reaction $(n=2 / 29,6.9 \%)$, pericarditis $(n=1 / 29,3.4 \%)$, meningitis $(n=1 / 29,3.4 \%)$ and encephalitis $(n=1 / 29,3.4 \%)$ (Additional file 1: Figure S1).

All patients with pneumonitis, one patient with pericarditis and one patient with infusion-related hypersensitivity reaction were admitted for acute respiratory failures. The three patients with myocarditis, one patient with infusion-related hypersensitivity reaction and one patient with colitis were admitted for hemodynamic failure. The two patients with hepatitis were admitted for hepatic failure. All patients with diabetes and hypophysitis were admitted for hydroelectrolytic disorders. Meningitis and encephalitis patients were admitted for neurologic failure. Two patients with nephritis and two patients with colitis were admitted for acute kidney injury, whereas the last colitis patient was admitted for hemorrhage requiring emergency endoscopic evaluation.

The clinical characteristics and underlying disease of irAE patients at ICU admission are described in Table 1.

ICI at the time of admission included nivolumab $(n=9 / 29,31 \%)$, pembrolizumab $(n=7 / 29,24.1 \%)$, ipilimumab $(n=5 / 29,17.2 \%)$ and the combination of ipilimumab and nivolumab in 6/29 (20.7\%) patients (Additional file 2: Figure S2 panel A).

Immune-related adverse events were different between anti-CTLA4, anti-PD(L)-1 and combination therapy $(p=0.028)$, with pneumonitis being more common in patients treated with anti- $\mathrm{PD}(\mathrm{L})-1$ ( $44 \%$ versus $0 \%$, $p=0.03)$, whereas colitis was only diagnosed in patients treated with anti-CTLA4 or combination therapy ( 0 versus $36 \%, p=0.027$ ) (Additional file 2: Figure S2 panel C).

Vasopressor was required for $7 / 29$ (24.1\%) patients including $2 / 29$ (6.9\%) patients with extra-corporeal membrane oxygenation and $1 / 29(3.4 \%)$ patient with renal replacement therapy. Oxygenation strategies included mechanical ventilation $(n=6,20.7 \%)$, non-invasive ventilation only $(n=2 / 29,6.9 \%)$ or high-flow nasal cannula $(n=2 / 29,6.9 \%)$ or both non-invasive devices $(n=1 / 29$, $3.4 \%)$. Renal replacement therapy without any other organ support was needed for $2 / 29(6.9 \%)$ patients. No organ support was required for $13 / 29(44.8 \%)$ patients admitted with metabolic disorder $(n=7 / 29,24.1 \%)$ or for monitoring and observation $(n=6 / 29,20.7 \%)$.

IrAEs were treated with steroids $(n=18 / 29,62.1 \%)$ and second-line immunosuppression was required for $3 / 29$ (10.3\%) patients (immunoglobulins and plasma exchange 
Table 1 Comparison of immune-related adverse events, intercurrent events and complications of tumor progression admissions

\begin{tabular}{|c|c|c|c|}
\hline & $\operatorname{IrAE}(n=29)$ & IntE $(n=39)$ & TumProg $(n=44)$ \\
\hline \multicolumn{4}{|l|}{ Demographics and comorbidities } \\
\hline Sex $=M(n, \%)$ & $19(66)$ & $22(56)$ & $27(61)$ \\
\hline Age (median [IQR]) & $62.7[52.9-71]$ & $67.5[61.9-74.1]$ & $57.8[45.5-67.8]$ \\
\hline \multicolumn{4}{|l|}{ Comorbidities $(n, \%)$} \\
\hline Hypertension & $11(38)$ & $25(64)$ & $13(30)$ \\
\hline Diabetes & $4(14)$ & $6(15)$ & $3(7)$ \\
\hline Cardiac failure & $3(10)$ & $5(13)$ & $4(9)$ \\
\hline COPD & $1(3)$ & $6(15)$ & $4(9)$ \\
\hline Thromboembolic venous disease & $5(17)$ & $7(18)$ & $7(16)$ \\
\hline \multicolumn{4}{|l|}{ Smoking status ( $n, \%)$} \\
\hline Never & $10(34)$ & $9(23)$ & $15(34)$ \\
\hline Past & $6(21)$ & $10(26)$ & $9(21)$ \\
\hline Active & $13(45)$ & $20(51)$ & $20(46)$ \\
\hline Weight loss (> $5 \mathrm{~kg}$ in the 3 preceding month) $(n, \%)$ & $6(21)$ & $10(26)$ & $15(34)$ \\
\hline \multicolumn{4}{|l|}{ Performance status ( $n, \%)$} \\
\hline$\leq 2$ & $23(79)$ & $31(79)$ & $30(68)$ \\
\hline$>2$ & $2(7)$ & $8(21)$ & $9(20)$ \\
\hline BMI $\left(\mathrm{kg} / \mathrm{m}^{2}\right)$ (median [IQR]) & $24.8[22.3-28.9]^{*}$ & $23.2[21.1-27.8]$ & $21.1[19-24.7]^{*}$ \\
\hline Length of symptoms before admission (days) (median [IQR]) & $7[3,14]^{*}$ & $2[0-4]^{* *}$ & $2[1-8.5]$ \\
\hline \multicolumn{4}{|l|}{ Oncological characteristics } \\
\hline \multicolumn{4}{|l|}{ Primary tumor site $(n, \%)$} \\
\hline Colorectal adenocarcinoma & $0(0)$ & $1(3)$ & $1(2)$ \\
\hline Endometrial carcinoma & $0(0)$ & $1(3)$ & $2(5)$ \\
\hline Prostate cancer & $0(0)$ & $0(0)$ & $1(2)$ \\
\hline Ovarian cancer & $1(3)$ & $2(5)$ & $0(0)$ \\
\hline Breast cancer & $0(0)$ & $0(0)$ & $2(5)$ \\
\hline Cervical cancer & $0(0)$ & $0(0)$ & $3(7)$ \\
\hline Squamous cell carcinoma & $0(0)$ & $0(0)$ & $1(2)$ \\
\hline Esophagus cancer & $0(0)$ & $0(0)$ & $1(2)$ \\
\hline Head and neck carcinoma & $0(0)$ & $9(23)$ & $6(14)$ \\
\hline Urothelial carcinoma & $5(17)$ & $7(18)$ & $4(9)$ \\
\hline Non-small cell lung cancer & $7(24)$ & $12(31)$ & $13(30)$ \\
\hline Small cell lung cancer & $0(0)$ & $0(0)$ & $1(2)$ \\
\hline Hodgkin lymphoma & $1(3)$ & $0(0)$ & $0(0)$ \\
\hline Melanoma & $14(48)$ & $7(18)$ & $9(20)$ \\
\hline Thymoma & $1(3)$ & $0(0)$ & $0(0)$ \\
\hline \multicolumn{4}{|l|}{ State at admission $(n, \%)$} \\
\hline Localized & $0(0)$ & $2(5)$ & $0(0)$ \\
\hline Locoregional & $4(14)$ & $6(15)$ & $3(7)$ \\
\hline Metastatic & $23(79)$ & $31(79)$ & $41(93)$ \\
\hline Number of metastatic sites (median [IQR]) & $2[1,3]$ & $2[1,3]$ & $2[1,3]$ \\
\hline Length from diagnosis (months) (median [IQR]) & $13.5[6.3-30.1]$ & $16.6[5.7-29.3]$ & $16[11.3-27.5]$ \\
\hline Number of previous chemotherapeutic lines (median [IQR]) & $1[0-1]$ & $1[0-2]$ & $1[1,2]$ \\
\hline \multicolumn{4}{|l|}{ Immune checkpoint inhibitors ( $n, \%)$} \\
\hline \multicolumn{4}{|l|}{ Anti-PD-1 } \\
\hline NIVOLUMAB & $9(31)$ & $19(49)$ & $22(50)$ \\
\hline PEMBROLIZUMAB & $7(24)$ & $13(33)$ & $8(18)$ \\
\hline SPARTALIZUMAB & $0(0)$ & $1(3)$ & $1(2)$ \\
\hline
\end{tabular}


Table 1 (continued)

\begin{tabular}{|c|c|c|c|}
\hline & $\operatorname{IrAE}(n=29)$ & IntE $(n=39)$ & TumProg $(n=44)$ \\
\hline \multicolumn{4}{|l|}{ Anti-PDL-1 } \\
\hline ATEZOLIZUMAB & $1(3)$ & $2(5)$ & $0(0)$ \\
\hline AVELUMAB & $0(0)$ & $2(5)$ & $2(5)$ \\
\hline DURVALUMAB & $1(3)$ & $1(3)$ & $4(9)$ \\
\hline \multicolumn{4}{|l|}{ Anti-CTLA4 } \\
\hline IPILIMUMAB & $5(17)^{*}$ & $1(3)$ & $2(5)$ \\
\hline TREMELIMUMAB & $0(0)$ & $0(0)$ & $1(2)$ \\
\hline Anti-CTLA4/Anti-PD-1: IPILIMUMAB/NIVOLUMAB & $6\left(21^{*}\right.$ & $0(0)$ & $4(9)^{*}$ \\
\hline Length from ICI initiation and ICU admission (days) (median [IQR]) & 56 [30-84] & $68[20.5-199.5]$ & $43.5[19-88.5]$ \\
\hline Length from last ICI dose (days) (median [IQR]) & $14[17,22]$ & $14.5[8.3-25.5]$ & $15.5[6.3-27.8]$ \\
\hline \multicolumn{4}{|l|}{ Clinical and biological characteristics at ICU admission } \\
\hline Blood pressure (systolic) (median [IQR]) & $129[112.5-146]$ & $124[91-146.5]$ & $123[109.5-132.5]$ \\
\hline Blood pressure (diastolic) (median [IQR]) & $72[60-82.5]$ & $69[59-90.5]$ & $71[64.5-81]$ \\
\hline Respiratory rate (median [IQR]) & $24[19,29]$ & $21[18-26.5]$ & $22.5[18,25]$ \\
\hline $\mathrm{SpO}_{2}$ (median (IQR) & $97[94.5-98]$ & 96 [93-98.8] & 97 [95-99] \\
\hline Glasgow score for coma (median [IQR]) & 15 [14.8-15] & $15[13,15]$ & $15[15-15]$ \\
\hline SOFA Day 1 (median [IQR]) & $2[1,4]$ & $4[1,6]$ & $3[3,5]$ \\
\hline Leucocytes (G/L) (median [IQR]) & $8.5[6.5-16.1]$ & $11.9[7.4-18]$ & $14.4[8.7-19.2]$ \\
\hline Neutrophils (G/L) (median [IQR]) & $5.3[3.9-13.9]^{*}$ & $10.2[6.1-16.2]^{*}$ & $12.3[7-17.8]^{*}$ \\
\hline Lymphocytes (G/L) (median [IQR]) & $1[0.8-1.6]$ & $0.7[0.5-1.6]$ & $0.8[0.4-1.4]$ \\
\hline Neutrophil/Lymphocyte ratio (median [IQR]) & $6[3.6-15.5]^{*}$ & $11.9[5.5-23.3]$ & $14.2[6.2-22.4]^{*}$ \\
\hline Hemoglobin (g/dL) (median [IQR]) & $11.7[10.3-13.2]^{*}$ & $11[10.2-12]$ & $9.9[8.6-11.3]^{* *}$ \\
\hline Platelets (G/L) (median [IQR]) & $305.5[214.3-402.3]$ & $271[209.5-375.8]$ & $288.5[211.8-384]$ \\
\hline Fibrinogen $(\mathrm{g} / \mathrm{L})$ (median $[\mathrm{IQR}])$ & $4.7[3.5-6]$ & $5.1[4.3-5.7]$ & $5.5[3.6-6.9]$ \\
\hline Prothrombin Time (\%) (median [IQR]) & $83[74-91]^{*}$ & $74[61-88]$ & $70.5[60-85]^{*}$ \\
\hline Creatinine $(\mu \mathrm{M})$ (median [IQR]) & $106.5[67-177.5]^{*}$ & $86[59.3-148]$ & $64[54-97]^{*}$ \\
\hline Nitrogen (mM) (median [IQR]) & $9.1[6.7-14.8]$ & $8[5.5-11.5]$ & $7.7[5.7-11.1]$ \\
\hline Lactate (mM) (median [IQR]) & $1.7[1.2-2.6]$ & $2[1.4-3.2]$ & $2.4[1.5-3.8]$ \\
\hline $\mathrm{pH}$ (median [IQR]) & $7.4[7.3-7.4]$ & $7.4[7.3-7.4]$ & $7.4[7.3-7.4]$ \\
\hline Bilirubin $(\mu \mathrm{M})$ (median [IQR]) & $8[6,12]$ & $10[7,14]$ & $10[7-15.5]$ \\
\hline \multicolumn{4}{|l|}{ Treatments in ICU and outcomes } \\
\hline ICU length of stay (days) (median [IQR]) & $4[1.3-8]$ & $2[1,4]$ & $3[1.1-5.3]$ \\
\hline Vasopressor therapy $(\mathrm{n}, \%)$ & $7(24)$ & $16(41)$ & $12(27)$ \\
\hline Mechanical ventilation $(n, \%)$ & $6(21)$ & $12(31)$ & $13(30)$ \\
\hline Length of mechanical ventilation (days) (median [IQR]) & $8[5.8-14.8]$ & $2.5[2-3.3]^{*}$ & $5[2,8]^{*}$ \\
\hline Non-invasive ventilation $(n, \%)$ & $7(24)$ & $8(21)$ & $9(21)$ \\
\hline Renal replacement therapy $(n, \%)$ & $3(10)$ & $1(3)$ & $2(5)$ \\
\hline CVVHF & $1(3)$ & $0(0)$ & $1(2)$ \\
\hline Hemodialysis & $2(7)$ & $1(3)$ & $1(2)$ \\
\hline Steroids $(n, \%)$ & $18(62)^{*}$ & $4(10)^{* *}$ & $17(39)$ \\
\hline ICU mortality $(n, \%)$ & $5(17)$ & $9(23)$ & $16(36)$ \\
\hline Limitations during ICU stay $(n, \%)$ & $4(14) *$ & $11(28)$ & $21(48)^{*}$ \\
\hline Discontinuation of $\mathrm{ICI}(n, \%)$ & $18(62)$ & $22(56)$ & $30(68)$ \\
\hline \multirow[t]{2}{*}{ One-year mortality $(n, \%)$} & $10(42)$ & $21(66)$ & $36(88)$ \\
\hline & $\begin{array}{l}*=p<0.05 \\
{ }^{*}=p<0.001 \text { against Others }\end{array}$ & $\begin{array}{l}*=p<0.05 \\
* *=p<0.001 \text { against irAE }\end{array}$ & $\begin{array}{l}{ }^{*}=p<0.05 \\
*^{*}=p<0.001 \text { against irAE }\end{array}$ \\
\hline
\end{tabular}

irAE immune-related adverse event, TumProg complication related to tumor progression, intE intercurrent event, $C O P D$ chronic obstructive pulmonary disease, ICI immune checkpoint inhibitor, ICU intensive care unit, CVVHF continuous veno-venous hemofiltration, SOFA Sequential Organ Failure Assessment, IQR interquartile range 
$(1 / 29,3.4 \%)$ immunoglobulins, plasma exchange and tacrolimus $(1 / 29,3.4 \%)$ and cyclophosphamide $(1 / 29,3.4 \%))$. All patients with diabetes, two patients with pneumonitis, and 6 patients with colitis $(n=1)$, hypophysitis $(n=1)$, myocarditis presenting with high-degree atrioventricular block $(n=1)$, meningitis $(n=1)$, pericarditis $(n=1)$ and hepatitis $(n=1)$ did not received steroids. Five out of 29 (17.2\%) irAE patients died during ICU stay. One patient with hepatitis died 33 days after his first dose of ipilimumab for melanoma without any steroid treatment. One patient died from severe myocarditis 16 days after his first dose of nivolumab for thymic carcinoma despite treatment with steroids, immunoglobulins, and plasma exchange. Two NSCLC patients died from pneumonitis within 2 months of pembrolizumab and nivolumab therapy after treatment with steroids $(n=1)$ or steroids and cyclophosphamide $(n=1)$. Lastly, one NSCLC patient died from fulminant hepatitis 2.5 months after nivolumab therapy onset and despite steroid treatment.

After ICU discharge, 8/29 (27.6\%) patients (diabetes $(n=2)$, hypophysitis $(n=1)$, meningitis $(n=1)$, infusion-related reaction $(n=1)$, colitis $(n=1)$, pneumonitis $(n=1)$, and pericarditis $(n=1))$ were readministered the same ICI without any recurrence of significant adverse event (one grade 1 eosinophilia). Among these patients, 3/8 (37.5\%) achieved complete responses, $2 / 8$ (25\%) patients had sustained partial responses, and tumor progression was diagnosed according to iRECIST for 3 (37.5\%) of them.

Ten out of $24(41.7 \%)$ irAE patients died before one year after ICU admission.
As described in the swimmer plot (Fig. 2), patients died within the ICU course $(n=5 / 29,17.2 \%)$ or quickly after discharge $(n=3 / 29,10.3 \%)$. No death was registered more than 3 months after ICU discharge and one lymphoma patient was still alive 5 years after an ICI-induced pneumonitis that required non-invasive ventilation in the ICU.

\section{Other reasons for ICU admission}

For 83 other patients, the final diagnosis was not related to irAE. They are described in Table 1 . Non-irAE diagnoses were mainly sepsis $(n=11 / 83,13.3 \%)$, pneumonia ( $n=10 / 83,12 \%)$, hemorrhage $(n=9 / 83,10.8 \%)$, cardiac failure $(n=7 / 83,8.4 \%$, including coronary event $(n=1)$, fluid overload and hypertension treated with diuretics only $(n=4)$, pericarditis with tumor cells on fluid examination $(n=1)$ and influenza-related myocarditis $(n=1))$, peritonitis $(n=5 / 83,6 \%)$, kidney failure $(n=4 / 83,4.8 \%)$, pulmonary embolism $(n=2 / 83,2.4 \%)$, and non-controlled tumor ( $n=31 / 83,37.3 \%)$.

Compared to other diagnoses, diagnosis of irAE was associated with melanoma (OR $=3.85$ [1.42-10.66], $p=0.004)$ and a neutrophil/lymphocyte ratio lower than $10(\mathrm{OR}=3.31$ [1.16-10.19], $p=0.018)$, whereas non-irAE complications were associated with head and neck cancer (no irAE admission, $p=0.011$ ).

Durations of treatment before ICU admission were not different between the groups.

The proportion of patients who stopped ICI treatment after ICU discharge was not different between the groups

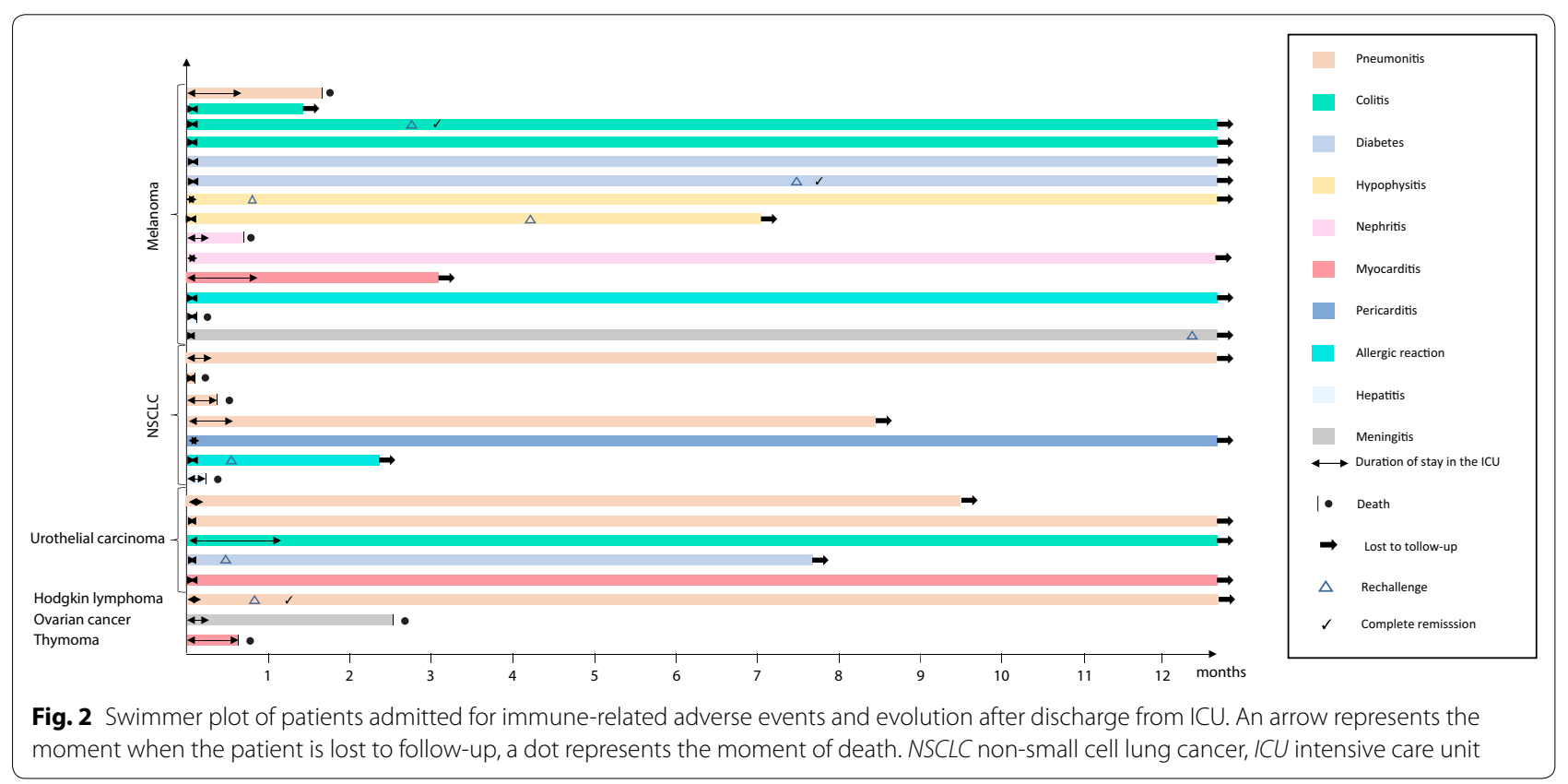


(18/29 (62.1\%), 22/39 (56.4\%) and 28/44 (63.6\%) for irAE, TumProg and intE, respectively, $p=0.942)$.

\section{Prognostic factors}

Mortality rate in the ICU was, respectively, $17.2 \%$ $(n=5 / 29), 23.1 \%(n=9 / 39)$ and $36.4 \%(n=16 / 44)$ for ICU admission related to irAE, intE and TumProg $(p=0.159)$.

Overall survival, censored at one year, was significantly higher for patients admitted with irAE compared to patients admitted for other reasons $(p=0.004)$. Specifically, survival for irAE patients was significantly better compared with TumProg patients $(p<0.001)$ and not significantly different compared with intE patients $(p=0.172)$ (Fig. 3).

Factors associated with one-year mortality in multivariate analysis (Table 2) were related to tumor site (NSCLC versus others $(\mathrm{OR}=1.28 \quad[1.07-1.52], \quad p=0.007))$, duration of ICI treatment before ICU admission $(\mathrm{OR}=0.973[0.952-0.994], p=0.014))$, reason for ICU admission (ICU admission related to a complication of tumor progression $(\mathrm{OR}=1.35$ [1.14-1.59], $p<0.001))$ and SOFA score at ICU admission $(\mathrm{OR}=1.05$ [1.03-1.08], $p<0.001)$.

Additional file 3 shows survival curves according to ICI molecule (panel A) and tumor site (panel B).

\section{Discussion}

This study describes patients admitted to the ICU after ICI treatment. The main result of our study is the better outcome for irAE patients compared with other reasons of ICU admission. Median survival exceeded one year for patients with irAE.

Immune checkpoint inhibitors have reshaped the standard of care in oncology wards and are increasingly encountered in intensive care units, as shown by the
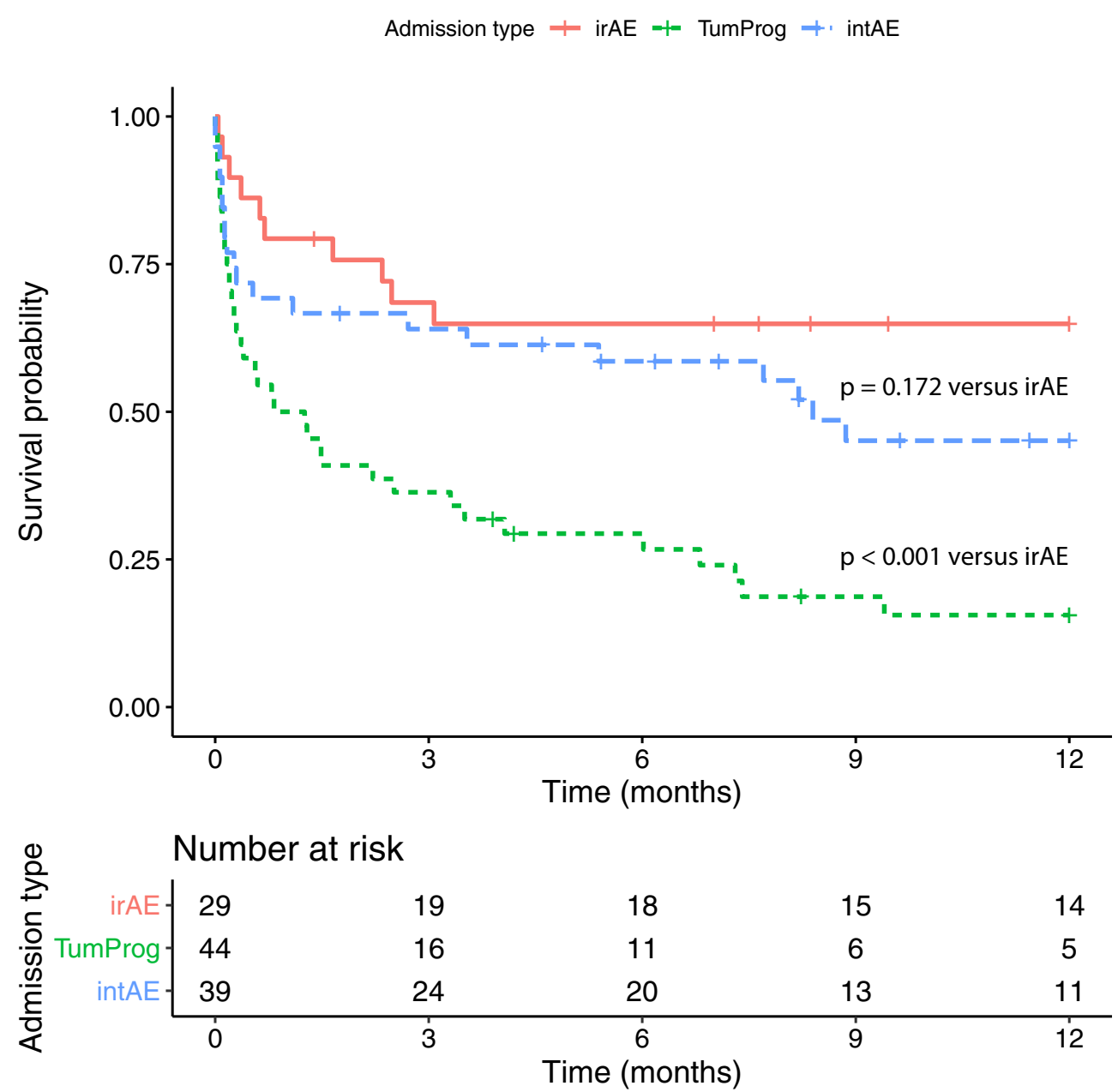

Fig. 3 Kaplan-Meier curves for overall survival of patients admitted for irAE compared to intE $(p=0.172)$ and TumProg patients $(p<0.001)$ (irAE versus others $p=0.004$ ). irAE immune-related adverse event, TumProg complication related to tumor progression, intE intercurrent event 
Table 2 Factors associated with 12-month mortality in univariate and multivariate analysis in patients admitted in the intensive care unit (ICU) within 60 days after last dose of immune checkpoint inhibitor (ICI)

OR for mortality (univariate logistic

OR for mortality

regression model)

\begin{tabular}{|c|c|c|}
\hline \multicolumn{3}{|l|}{ Reason for admission } \\
\hline Immune-related adverse event & Ref & \\
\hline Intercurrent complication & $1.27[0.98-1.65]$ & \\
\hline Complication of tumor progression & $1.59[1.29-1.94]$ & $1.35[1.14-1.59]$ \\
\hline \multicolumn{3}{|l|}{ Demographics and comorbidities } \\
\hline Weight loss (>5 kg in the 3 preceding months) & $1.24[1.00-1.52]$ & \\
\hline Performance status $>2$ & $1.27[1.01-1.60]$ & $1.15[0.94-1.40]$ \\
\hline \multicolumn{3}{|l|}{ Oncological characteristics } \\
\hline \multicolumn{3}{|l|}{ Primary tumor site } \\
\hline Non-small cell lung cancer & $1.24[1.02-1.51]$ & $1.28[1.07-1.52]$ \\
\hline Melanoma & $0.66[0.54-0.78]$ & \\
\hline Metastatic disease at admission & $1.46[1.10-1.93]$ & \\
\hline Length from $\mathrm{ICl}$ initiation (month) & $0.974[0.951-0.997]$ & $0.973[0.952-0.994]$ \\
\hline \multicolumn{3}{|l|}{ Clinical and biological characteristics at ICU admission } \\
\hline SOFA Day 1 & $1.04[1.01-1.07]$ & $1.05[1.03-1.08]$ \\
\hline Neutrophil-lymphocyte ratio > 10 & $1.33[1.09-1.62]$ & \\
\hline \multicolumn{3}{|l|}{ Treatments in ICU } \\
\hline Mechanical ventilation & $1.19[0.97-1.46]$ & \\
\hline Non-invasive ventilation & $1.25[1.01-1.55]$ & \\
\hline Renal replacement therapy & $1.16[0.79-1.71]$ & \\
\hline Steroids & $1.12[0.92-1.36]$ & \\
\hline
\end{tabular}

Hazard ratios and their $95 \%$ confidence interval are shown for factors associated with 12-month mortality in univariate and multivariate analyses

exponential increase of the number of admissions in our study. Intensivists need to be aware of these new treatments leading to high survival rates with a good quality of life, even in patients with advanced cancer [1]. These treatments, leading to an increased immune response, have been associated with several immune-related disorders [29], most of which remain low grade and can be easily managed. However, toxicity-related mortality under ICI can reach $0.36 \%$ for anti-PD1 and $1.23 \%$ for anti-PD1/ anti-CTLA4 combination [30]. With an increased number of treated patients, number of fatal irAEs reported has increased more than threefold between 2015 and 2017 [30]. Therefore, intensivists should be aware of such severe complications with potential good outcomes after early diagnosis and treatment. Indeed, other complications may be easily ruled out with a simple diagnostic strategy relying on a close collaboration between oncologists and intensivists. Then immunosuppressive treatment including steroids should be quickly prescribed to reverse irAE [20, 31, 32] Systemic steroids are recommended for grade 3 and 4 immune-related adverse events $[20,21,32,33]$. For steroid-refractory irAEs, a personalized management based on the predominant immune infiltrate is advised $[22,23]$. However, there are not yet recommendations for salvage therapy when steroids fail to decrease toxicity. Thus, a close collaboration between oncologists and intensivists must be of importance. Based on treatment approaches for primary autoimmune disorders, early treatment by anti-TNF $\alpha$ in colitis $[24,34]$ and plasma exchange in neurological toxicities [25] have been advocated.

The second result of importance of the study is the kind of admitted patients. Although ICI are usually prescribed for metastatic disease within first- or second-line treatment, patients may keep high performance status. Such patients could benefit from ICU admission. Moreover, in this study as in previous ones, ICI could be safely readministered and could lead to long-term responses [35, 36]. Also, some patients with highly severe $\mathrm{AE}$ and in whom ICI was stopped have shown long-term response or stability. Immune-related adverse events have been shown to correlate with response rate, and some studies describe a better prognosis in patients experiencing irAEs [37-39]. Therefore, such adverse events do not lead to palliative treatment. However, performance status should be evaluated before ICU admission as it has been consistently associated with mortality in intensive care cancer patients [40]. 
Also, this study describes the clinical heterogeneity of such patients in the context of intensive care; the 3 most frequent diagnoses (pneumonitis, colitis and cardiac disorders) representing only approximately half of the patients. These adverse events have been already described [2]. Particularly, colitis has been associated with anti-CTLA4, whereas pneumonitis has been related to anti-PD1 treatment [41], as shown in our study. Moreover, we confirm the risk of severe AE when ICI combinations are used [2, 30, 42]. If our small sample size does not allow us to compare mortality across the different types of irAEs, larger cohorts from outside of the ICU have described high mortality rates [30] in myocarditis [16-19], pneumonitis [4-6] and hepatitis [11-13] patients. Although rarely lethal, colitis has been reported as the first cause of treatment-related death in patients under anti-CTLA4 therapy [30].

Some irAEs, such as diabetic ketoacidosis or acute hypophysitis, carry a good prognosis compared with more frequent conditions leading to ICU admissions in oncological patients. Such diagnoses should be easily raised and managed by intensivists even in patients with advanced cancer. Moreover, such irAEs can be managed without immunosuppressive treatment [36]. In our cohort, patients admitted for diabetes ketoacidosis and several other immune-related events did not receive steroids, highlighting the need for raising awareness of this kind of complication and establishing multidisciplinary protocols for the treatment of these patients, especially the ones who are critically ill.

There are several limitations in this study. First, this was a retrospective study including only patients admitted to the ICU. Although irAEs are rare, this study could include 112 patients treated with ICI and 29 irAEs. Compared to case reports, this is the largest study describing irAEs in the ICU setting. Moreover, comparison with other reasons of ICU admission in patients receiving ICI could be performed.

In such retrospective studies, admission bias remains the most important limitation. Indeed, most patients in our study had a high performance status that may not reflect all cancer patients, preventing a direct comparison to patients treated with conventional chemotherapies admitted in the ICU. However patients admitted to the ICU for non-immune-related reasons while receiving a treatment by an ICI have been compared to patients admitted for irAEs.

Third, we chose a timeframe of 60 days from the last dose to admission in the ICU. If time from first dose to onset of irAE has been deeply studied and varies largely among irAEs [2], time from last dose to irAE has been seldom reported. On the one hand, some irAEs have been reported up to 2 years after ICI cessation [43]. On the other hand, time from last dose to irAE does not seem to vary much between early and late-occurring irAEs, with a median time of 2 weeks in both colitis [44] and nephritis [45], similar to our findings. Thus, our 2-month timeframe between last ICI dose and admission in the ICU unlikely resulted in a significant admission bias, whereas it prevented issues concerning imputability of the ICI or comparability between the irAE group and patients admitted for non-immune-related reasons long after cessation of ICI.

Lastly, irAEs were heterogeneous and no risk factor could be determined for each type of irAE. However, the aim of our study was to increase knowledge of this kind of adverse events for intensivists. In the future, with the increasing number of ICI-treated patients, new combinations and probably higher risk of ICU admission, adverse events will be better evaluated [46].

\section{Conclusions}

In conclusion, intensivists should be aware of irAEs even in patients with advanced cancer. Such adverse events, with early diagnosis and treatment, may be associated with good outcomes even in the case of severe organ failure and in metastatic settings. These results justify ICU admission for such patients, but a close collaboration between oncologists and intensivists for diagnostic procedure and immunosuppressive treatment remains essential.

\section{Supplementary information}

Supplementary information accompanies this paper at https://doi. org/10.1186/s13613-020-00761-w.

Additional file 1: Figure S1. Eligibility and classification of patients admitted to the ICU over the study period. ICI: Immune checkpoint inhibitor.

Additional file 2: Figure S2. A: Pie chart of $\mathrm{ICl}$ treatments $(n=112)$. B: Pie chart of primary tumor sites $(n=112)$. C: Radar chart of types of irAE according to class of $\mathrm{ICl}(n=29)$. Each class of $\mathrm{ICl}$ is represented in a different color and the number of each type of complication is featured on an axis. D: Status at ICU discharge according to the type of irAE $(n=29)$. The number patients alive and dead at discharge from ICU for each type of complication is featured on axis in blue and yellow color.

Additional file 3: Figure S3. Kaplan-Meier curves for overall survival stratified for class of immune checkpoint inhibitor $(p=0.19)$ and tumor type $(p<0.001)$

\section{Abbreviations}

CTLA-4: Cytotoxic T-lymphocyte antigen 4; ICl: Immune checkpoint inhibitors; ICU: Intensive care unit; IntE: Intercurrent event; IRAE: Immune-related adverse events; NSCLC: Non-small cell lung cancer; PD-1: Programmed cell death 1; PDL-1: Programmed cell death ligand 1; SOFA: Sequential Organ Failure Assessment; TumProg: Tumor progression.

\section{Acknowledgements}

An abstract from part of the results has been presented at "Réanimation 2020" French Intensive care congress on the 7th of February 2020 in Paris, France. 


\section{Authors' contributions}

Conception, design and methodology: AJ, VL, JMM, EA. Data collection: AJ, ASi, ASt. Interpretation of data: AJ, VL, AS. Classification of patients: AJ, VL. Statistical analysis, AJ. Writing: AJ, VL. Review: EA, SO, AVB, GG. All authors read and approved the final manuscript.

\section{Funding}

No funding was received for this work.

\section{Availability of data and materials}

The datasets used and analyzed during the current study are available from the corresponding author on reasonable request.

\section{Ethics approval and consent to participate}

The appropriate Institutional Review Board approved the study in accordance with the declaration of Helsinki (CE SRLF 19-15) and the French data protection authority (CNIL, authorization no. 2211482, Paris, France). The need for informed consent was waived due to the retrospective design of the study.

\section{Consent for publication}

Not applicable.

\section{Competing interests}

Dr. Oudard reported expert testimony and consultancy fees and/or provided lectures for Pfizer, Bayer, MSD, Novartis, IPSEN and Merck.Dr. Michot reported advisory board membership for Bristol-Myers Squibb, Pfizer, Roche, Novartis, Janssen, AstraZeneca, Celgene, and Gilead.Dr. Lambotte reported expert testimony and consultancy fees from Bristol-Myers Squibb France, MSD, and AstraZeneca; consultancy fees from Genzyme; and expert testimony fees from Janssen.No other disclosures were reported.

\section{Author details}

${ }^{1}$ U1138. INSERM, Équipe 11 labellisée Ligue Nationale Contre Le Cancer, « Metabolism, Cancer \& Immunity », Centre de Recherche Des Cordeliers, 15. rue de l'École de Médecine, 75006 Paris, France. ${ }^{2}$ Metabolomics and Cell Biology Platforms, Gustave Roussy Cancer Campus, Villejuif, France. ${ }^{3}$ Service de Réanimation Médicale, Hôpital Saint-Louis, Assistance Publique Hôpitaux de Paris, Paris, France. ${ }^{4}$ Service d'oncologie Médicale, Hôpital Européen Georges Pompidou, Assistance Publique Hôpitaux de Paris, Paris, France. ${ }^{5}$ Université de Paris, Paris, France. ${ }^{6}$ Service de Médecine Intensive Réanimation, Département Interdisciplinaire de L'Organisation Des Parcours Patient, Institut Gustave Roussy, Villejuif, France. ${ }^{7}$ Service de Médecine Intensive Réanimation, Hôpital Ambroise Paré, Assistance Publique Hôpitaux de Paris, Boulogne Billancourt, France. ${ }^{8}$ INSERM UMR1018, Team Kidney and Heart, CESP, Villejuif, France. ${ }^{9}$ UFR des Sciences de la Santé Simone Veil, Université Versailles Saint Quentin, Versailles, France. ${ }^{10}$ Faculté de médecine, Université Paris Saclay, Le Kremlin-Bicêtre, France. ${ }^{11}$ Département D'innovations Thérapeutiques Et D'essais Précoces (DITEP), Institut Gustave Roussy, Villejuif, France. ${ }^{12}$ Service de Médecine Interne Et D'immunologie Clinique, Hôpital Bicêtre, Assistance Publique Hôpitaux de Paris, 94270 Le Kremlin-Bicêtre, France. ${ }^{13}$ Inserm, CEA, Centre de Recherche en Immunologie Des Infections Virales Et Des Maladies Auto-Immunes ImVA, UMR1 184, Université Paris-Saclay, 94270 Le Kremlin Bicêtre, France. ${ }^{14}$ U1 153, INSERM, Équipe ECSTRA, Biostatistiques Et Épidémiologie Clinique, Université de Paris, Paris, France.

Received: 7 July 2020 Accepted: 8 October 2020

Published online: 16 October 2020

\section{References}

1. Hirsch L, Zitvogel L, Eggermont A, Marabelle A. PD-Loma: a cancer entity with a shared sensitivity to the PD-1/PD-L1 pathway blockade. Br J Cancer. 2019;120(1):3-5

2. Martins F, Sofiya L, Sykiotis GP, Lamine F, Maillard M, Fraga M, et al. Adverse effects of immune-checkpoint inhibitors: epidemiology, management and surveillance. Nat Rev Clin Oncol. 2019;16(9):563-80.

3. Geraud A, Gougis P, Vozy A, Anquetil C, Allenbach Y, Romano E, et al. Clinical pharmacology and interplay of immune checkpoint agents: a Yin-Yang balance. Annu Rev Pharmacol Toxicol. 2020.
4. Khunger M, Rakshit S, Pasupuleti V, Hernandez AV, Mazzone P, Stevenson $J$, et al. Incidence of pneumonitis with use of programmed death 1 and programmed death-ligand 1 inhibitors in non-small cell lung cancer. Chest. 2017;152(2):271-81.

5. Naidoo J, Wang X, Woo KM, lyriboz T, Halpenny D, Cunningham J, et al. Pneumonitis in patients treated with anti-programmed death-1/programmed death ligand 1 therapy. J Clin Oncol. 2017;35(7):709-17.

6. Sears CR, Peikert T, Possick JD, Naidoo J, Nishino M, Patel SP, et al. Knowledge gaps and research priorities in immune checkpoint inhibitor-related pneumonitis. An Official American Thoracic Society Research Statement. Am J Respir Crit Care Med. 2019;200(6):e31-43.

7. Kao JC, Liao B, Markovic SN, Klein CJ, Naddaf E, Staff NP, et al. neurological complications associated with anti-programmed death 1 (PD-1) antibodies. JAMA Neurol. 2017;74(10):1216.

8. Graus F, Dalmau J. Paraneoplastic neurological syndromes in the era of immune-checkpoint inhibitors. Nat Rev Clin Oncol. 2019;16(9):535-48.

9. Moreira A, Loquai C, Pföhler C, Kähler KC, Knauss S, Heppt MV, et al. Myositis and neuromuscular side-effects induced by immune checkpoint inhibitors. Eur J Cancer Oxf Engl (1990). 1990;2019(106):12-23.

10. Allenbach Y, Anquetil C, Manouchehri A, Benveniste O, Lambotte O, Lebrun-Vignes B, et al. Immune checkpoint inhibitor-induced myositis, the earliest and most lethal complication among rheumatic and musculoskeletal toxicities. Autoimmun Rev. 2020;19(8):102586.

11. Suzman DL, Pelosof L, Rosenberg A, Avigan MI. Hepatotoxicity of immune checkpoint inhibitors: An evolving picture of risk associated with a vital class of immunotherapy agents. Liver Int. 2018;38(6):976-87.

12. Riveiro-Barciela M, Barreira-Díaz A, Vidal-González J, Muñoz-Couselo E, Martínez-Valle F, Viladomiu L, et al. Immune-related hepatitis related to checkpoint inhibitors: clinical and prognostic factors. Liver Int. 2020;40(8):1906-16.

13. Peeraphatdit (Bee) T, Wang J, Odenwald MA, Hu S, Hart J, Charlton MR Hepatotoxicity from immune checkpoint inhibitors: a systematic review and management recommendation. Hepatology. 2020;72(1):315-29.

14. Varricchi G, Galdiero MR, Tocchetti CG. Cardiac toxicity of immune checkpoint inhibitors: cardio-oncology meets immunology. Circulation. 2017;136(21):1989-92.

15. Ball S, Ghosh RK, Wongsaengsak S, Bandyopadhyay D, Ghosh GC, Aronow WS, et al. Cardiovascular toxicities of immune checkpoint inhibitors. J Am Coll Cardiol. 2019;74(13):1714-27.

16. Bonaca MP, Olenchock BA, Salem J-E, Wiviott SD, Ederhy S, Cohen A, et al. Myocarditis in the setting of cancer therapeutics: proposed case definitions for emerging clinical syndromes in cardio-oncology. Circulation. 2019;140(2):80-91.

17. Moslehi JJ, Salem J-E, Sosman JA, Lebrun-Vignes B, Johnson DB. Increased reporting of fatal immune checkpoint inhibitor-associated myocarditis. Lancet Lond Engl. 2018:391(10124):933.

18. Mahmood SS, Fradley MG, Cohen JV, Nohria A, Reynolds KL, Heinzerling LM, et al. Myocarditis in patients treated with immune checkpoint inhibitors. J Am Coll Cardiol. 2018;71(16):1755-64.

19. Johnson DB, Balko JM, Compton ML, Chalkias S, Gorham J, Xu Y, et al. Fulminant myocarditis with combination immune checkpoint blockade. N Engl J Med. 2016;375(18):1749-55.

20. Brahmer JR, Lacchetti C, Schneider BJ, Atkins MB, Brassil KJ, Caterino JM, et al. Management of immune-related adverse events in patients treated with immune checkpoint inhibitor therapy: American Society of Clinical Oncology Clinical Practice Guideline. J Clin Oncol. 2018;36(17):1714-68.

21. on behalf of the Society for Immunotherapy of Cancer Toxicity Management Working Group, Puzanov I, Diab A, Abdallah K, Bingham $\mathrm{CO}$, Brogdon C, et al. Managing toxicities associated with immune checkpoint inhibitors: consensus recommendations from the Society for Immunotherapy of Cancer (SITC) Toxicity Management Working Group. J Immunother Cancer. 2017;5(1):95.

22. Martins F, Sykiotis GP, Maillard M, Fraga M, Ribi C, Kuntzer T, et al. New therapeutic perspectives to manage refractory immune checkpointrelated toxicities. Lancet Oncol. 2019;20(1):e54-64.

23. Esfahani K, Elkrief A, Calabrese C, Lapointe R, Hudson M, Routy B, et al. Moving towards personalized treatments of immune-related adverse events. Nat Rev Clin Oncol. 2020;1-12.

24. Johnson DH, Zobniw CM, Trinh VA, Ma J, Bassett RL, Abdel-Wahab N, et al. Infliximab associated with faster symptom resolution compared with 
corticosteroids alone for the management of immune-related enterocolitis. J Immunother Cancer. 2018;6(1):103.

25. Safa H, Johnson DH, Trinh VA, Rodgers TE, Lin H, Suarez-Almazor ME, et al. Immune checkpoint inhibitor related myasthenia gravis: single center experience and systematic review of the literature. J Immunother Cancer. 2019;7(1):319

26. Taccone FS, Artigas AA, Sprung CL, Moreno R, Sakr Y, Vincent J-L. Characteristics and outcomes of cancer patients in European ICUs. Crit Care Lond Engl. 2009;13(1):R15.

27. Michot J-M, Lappara A, Le Pavec J, Simonaggio A, Collins M, De Martin E, et al. The 2016-2019 ImmunoTOX assessment board report of collaborative management of immune-related adverse events, an observational clinical study. Eur J Cancer Oxf Engl. 1990;2020(130):39-50.

28. Seymour L, Bogaerts J, Perrone A, Ford R, Schwartz LH, Mandrekar S, et al. iRECIST: guidelines for response criteria for use in trials testing immunotherapeutics. Lancet Oncol. 2017;18(3):e143-52.

29. Xu C, Chen Y-P, Du X-J, Liu J-Q, Huang C-L, Chen L, et al. Comparative safety of immune checkpoint inhibitors in cancer: systematic review and network meta-analysis. BMJ. 2018;363:k4226.

30. Wang DY, Salem J-E, Cohen JV, Chandra S, Menzer C, Ye F, et al. Fatal toxic effects associated with immune checkpoint inhibitors: a systematic review and meta-analysis. JAMA Oncol. 2018:4(12):1721.

31. Groupe de Recherche en Reanimation Respiratoire du patient d'OncoHématologie (Grrr-OH), Lemiale V, Meert A-P, Vincent F, Darmon M, Bauer PR, et al. Severe toxicity from checkpoint protein inhibitors: What intensive care physicians need to know? Ann Intensive Care. 2019;9(1):25.

32. Thompson JA, Schneider BJ, Brahmer J, Andrews S, Armand P, Bhatia S, et al. Management of immunotherapy-related toxicities, version 1.2019. J Natl Compr Cancer Netw JNCCN. 2019;17(3):255-89.

33. Champiat S, Lambotte O, Barreau E, Belkhir R, Berdelou A, Carbonnel F, et al. Management of immune checkpoint blockade dysimmune toxicities: a collaborative position paper. Ann Oncol. 2016;27(4):559-74.

34. Perez-Ruiz E, Minute L, Otano I, Alvarez M, Ochoa MC, Belsue V, et al. Prophylactic TNF blockade uncouples efficacy and toxicity in dual CTLA-4 and PD-1 immunotherapy. Nature. 2019;569(7756):428-32.

35. Simonaggio A, Michot JM, Voisin AL, Pavec JL, Collins M, Lallart A, et al. Evaluation of readministration of immune checkpoint inhibitors after immune-related adverse events in patients with cancer. JAMA Oncol. 2019;5(9):1310-7.

36. Cuzzubbo S, Tetu P, Guegan S, Ursu R, Belin C, Villaros LS, et al. Reintroduction of immune-checkpoint inhibitors after immune-related meningitis: a case series of melanoma patients. J Immunother Cancer. 2020;8(2):e001034.

37. Weber JS, Hodi FS, Wolchok JD, Topalian SL, Schadendorf D, Larkin J, et al. Safety profile of nivolumab monotherapy: a pooled analysis of patients with advanced melanoma. J Clin Oncol Off J Am Soc Clin Oncol. 2017;35(7):785-92.

38. Haratani K, Hayashi H, Chiba Y, Kudo K, Yonesaka K, Kato R, et al. Association of immune-related adverse events with nivolumab efficacy in nonsmall-cell lung cancer. JAMA Oncol. 2018:4(3):374-8.

39. Das S, Johnson DB. Immune-related adverse events and anti-tumor efficacy of immune checkpoint inhibitors. J Immunother Cancer. 2019:7(1):306.

40. Azevedo LCP, Caruso P, Silva UVA, Torelly AP, Silva E, Rezende E, et al. Outcomes for patients with cancer admitted to the ICU requiring ventilatory support: results from a prospective multicenter study. Chest. 2014;146(2):257-66

41. Khoja L, Day D, Wei-Wu Chen T, Siu LL, Hansen AR. Tumour- and class-specific patterns of immune-related adverse events of immune checkpoint inhibitors: a systematic review. Ann Oncol. 2017;28(10):2377-85.

42. Chan KK, Bass AR. Autoimmune complications of immunotherapy: pathophysiology and management. BMJ. 2020. 369. https://www.bmj.com/ content/369/bmj.m736. Accessed 23 July 2020.

43. Couey MA, Bell RB, Patel AA, Romba MC, Crittenden MR, Curti BD, et al. Delayed immune-related events (DIRE) after discontinuation of immunotherapy: diagnostic hazard of autoimmunity at a distance. J Immunother Cancer. 2019;7(1):165.

44. Soularue E, Lepage P, Colombel JF, Coutzac C, Faleck D, Marthey L, et al. Enterocolitis due to immune checkpoint inhibitors: a systematic review. Gut. 2018:67(11):2056-67.

45. Cortazar FB, Kibbelaar ZA, Glezerman IG, Abudayyeh A, Mamlouk O, Motwani SS, et al. Clinical features and outcomes of immune checkpoint inhibitor-associated AKI: a multicenter study. J Am Soc Nephrol JASN. 2020;31(2):435-46.

46. Tang J, Yu JX, Hubbard-Lucey VM, Neftelinov ST, Hodge JP, Lin Y. The clinical trial landscape for PD1/PDL1 immune checkpoint inhibitors. Nat Rev Drug Discov. 2018;17(12):854-5.

\section{Publisher's Note}

Springer Nature remains neutral with regard to jurisdictional claims in published maps and institutional affiliations.

\section{Submit your manuscript to a SpringerOpen ${ }^{\circ}$ journal and benefit from:}

- Convenient online submission

- Rigorous peer review

- Open access: articles freely available online

- High visibility within the field

- Retaining the copyright to your article

Submit your next manuscript at $\boldsymbol{\nabla}$ springeropen.com 